\title{
Clinico-pathological and transcriptomic determinants of SLFN11 expression in invasive breast carcinoma
}

\author{
Gabriele Zoppoli ${ }^{1 *}$, Sylvain Brohee ${ }^{2}$, Christine Desmedt ${ }^{2}$, Christos Sotiriou ${ }^{2}$, Alberto Ballestrero ${ }^{1}$ \\ From Breast Cancer Immunotherapy Symposium (BRECIS), part of the Sidra Symposia Series, held in partner- \\ ship with the Society for Immunotherapy of Cancer \\ Doha, Qatar. 13-14 April 2015
}

SLFN11 is a putative DNA/RNA helicase we discovered as causally associated with sensitivity to DNA damaging agents, such as platinum salts, topoisomerase I and II inhibitors, and other alkylators in the NCI-60 panel of cancer cell lines [1]. Later, SLFN11 was identified as an early interferon response gene, in association with HIV infection [2]. Here we assessed SLFN11 determinants in a gene expression meta-set of 5,061 breast cancer patients annotated with clinical data and multigene signatures obtained with the package genefu [3]. By correlation analysis, we found 537 transcripts above the 95th percentile of Pearson's coefficients with SLFN11, identifying "immune response", "lymphocyte activation", and "T cell activation" as top Gene Ontology enriched processes [4]. Through multiple correspondence analysis, we discovered a subgroup of patients characterized by high SLFN11 levels, ER negativity, basal phenotype, elevated CD3D, STAT1 signature [5], and young age. Fitting a penalized maximum likelihood lasso regression model [6], we found a strong multivariable association of SLN11 with the stroma 1 and stroma 2 signatures $[7,8]$, associated with basal cancer and response to chemotherapy in ER- tumors. Finally, using Cox proportional hazard regression, ER-, high proliferation, high SLFN11 patients undergoing chemotherapy treatment showed a significantly longer disease-free interval than other patient categories included in our model.

\section{Authors' details}

${ }^{1}$ Department of Internal Medicine (DiMI), University of Genova, Genova, Italy. ${ }^{2}$ Breast Cancer Translational Research Laboratory J.C. Heuson, Institut Jules Bordet, Bruxelles, Belgium.

${ }^{1}$ Department of Internal Medicine (DiMI), University of Genova, Genova, Italy Full list of author information is available at the end of the article
Published: 14 August 2015

\section{References}

1. Zoppoli G, Regairaz M, Leo E, Reinhold WC, Varma S, Ballestrero A, Doroshow JH, Pommier Y: Putative DNA/RNA helicase Schlafen-11 (SLFN11) sensitizes cancer cells to DNA-damaging agents. Proc Natl Acad Sci U S A 2012, 109(37):15030-5.

2. Li M, Kao E, Gao X, Sandig H, Limmer K, Pavon-Eternod M, Jones TE, Landry S, Pan T, Weitzman MD, David M: Codon-usage-based inhibition of HIV protein synthesis by human schlafen 11 . Nature 2012 , 491(7422):125-8.

3. Haibe-Kains B, Schroeder M, Bontempi G, Sotiriou C, Quackenbush J: genefu: Relevant Functions for Gene Expression Analysis, Especially in Breast Cancer. 2014, R package version 1.16.0.

4. Huang da W, Sherman BT, Lempicki RA: Systematic and integrative analysis of large gene lists using DAVID bioinformatics resources. Nat Protoc 2009, 4(1):44-57.

5. Desmedt C, Haibe-Kains B, Wirapati P, Buyse M, Larsimont D, Bontempi G, Delorenzi M, Piccart M, Sotiriou C: Biological processes associated with breast cancer clinical outcome depend on the molecular subtypes. Clin Cancer Res 2008, 14(16):5158-65.

6. Friedman J, Hastie T, Tibshirani R: Regularization Paths for Generalized Linear Models via Coordinate Descent. J Stat Softw 2010, 33(1):1-22.

7. Farmer $\mathrm{P}$, Bonnefoi $\mathrm{H}$, Anderle $\mathrm{P}$, Cameron $\mathrm{D}$, Wirapati $\mathrm{P}$, Becette $\mathrm{V}$, Andr $\tilde{\Theta} \odot$ S, Piccart M, Campone M, Brain E, Macgrogan G, Petit T, Jassem J, Bibeau F, Blot E, Bogaerts J, Aguet M, Bergh J, Iggo R, Delorenzi M: A stroma-related gene signature predicts resistance to neoadjuvant chemotherapy in breast cancer. Nat Med 2009, 15(1):68-74.

8. Finak $G$, Bertos $N$, Pepin F, Sadekova $S$, Souleimanova M, Zhao H, Chen $H$, Omeroglu G, Meterissian S, Omeroglu A, Hallett M, Park M: Stromal gene expression predicts clinical outcome in breast cancer. Nat Med 2008, 14(5):518-27.

doi:10.1186/2051-1426-3-S1-03

Cite this article as: Zoppoli et al:: Clinico-pathological and transcriptomic determinants of SLFN11 expression in invasive breast carcinoma. Journal for ImmunoTherapy of Cancer 2015 3(Suppl 1):03.
C Biomed Central

(c) 2015 Zoppoli et al. This is an Open Access article distributed under the terms of the Creative Commons Attribution License (http:// creativecommons.org/licenses/by/4.0), which permits unrestricted use, distribution, and reproduction in any medium, provided the original work is properly cited. The Creative Commons Public Domain Dedication waiver (http://creativecommons.org/publicdomain/ zero/1.0/) applies to the data made available in this article, unless otherwise stated. 